\title{
DEL MONOCULTIVO EXPORTADOR A LAS CADENAS GLOBALES DE VALOR: UNA MIRADA HOLÍSTICA A 25 AÑOS DE ÉXITOS Y DESAFÍOS
}

\author{
VELIA GOVAERE VICARIOLI \\ Observatorio de Comercio Exterior, \\ Universidad Estatal a Distancia, Costa Rica \\ vgovaere@gmail.com
}

\section{RESUMEN}

Como resultado de 25 años de apertura comercial nuestro país cuenta con una amplia oferta exportable, múltiples destinos de exportación y es uno de los primeros países de América Latina en atracción de inversión extranjera. Esto ha tenido impacto directo en el desarrollo socio-económico del país con la consecuente transformación productiva del país. Sin embargo, estas transformaciones no cuentan con las condiciones de un entorno de negocio competitivo, infraestructura adecuada, una oferta laboral acorde a nuestro desempeño exportador y un encadenamiento apropiado de las PYMES con nuestro esfuerzo exportador. Nuestro desempeño de comercio exterior se acerca a un techo de limitaciones y desafíos que nacen de décadas de insuficientes esfuerzos redistributivos, escasa inversión en educación e infraestructura y del deterioro de nuestras condiciones sociales. Todo eso apunta a un enfoque más holístico del comercio.

PALABRAS CLAVE: APERTURA COMERCIAL, COMERCIO EXTERIOR, TRANSFORMACIONES PRODUCTIVAS, DESEMPEÑO EXPORTADOR, PEQUEÑA Y MEDIANA EMPRESA (PYMES).

\section{ABSTRACT}

After 25 years of market opening, Costa Rica has built up a broad array of exports and markets for its products, and it ranks among the most attractive countries in Latin America for direct foreign investment. This has had a direct impact on the country's socioeconomic development, which in turn has deeply transformed its productive sectors. These changes, however, are not fully supported by a competitive business environment, adequate infrastructure, a labor supply suited to respond to our exporting performance, or optimal productive chains of s with our export production. Export performance is reaching its upper limit, fraught with challenges borne of decades of inefficient redistributive policies, an inadequate regulatory system, lack of investment in education and infrastructure, and a deteriorated social fabric. All of this points to the need for a more holistic approach to trade.

KEYWORDS: MARKET OPENING, FOREIGN TRADE, PRODUCTIVE TRANSFORMATION, EXPORT PERFORMANCE, SMALL AND MEDIUM SIZE ENTERPRISE (SMES).

\section{INTRODUCCIÓN}

Costa Rica, a pesar de su pequeño tamaño y de su presencia en un medio centroamericano con profundas brechas socioeconómicas, exhibe, sin embargo, índices de desempeño comercial que son referencia hemisférica. De esa manera, el comercio exterior se ha ido convirtiendo en un componente cada vez más decisivo de su desarrollo, que para ser integral deberá desarrollar una competitividad interna y un equilibrio social que no sea contraste, con su capacidad comercial. Desde 1985 hasta la fecha, el país ha ido construyendo el andamiaje de una exitosa inserción al comercio internacional, que ha llegado hasta posicionarla, actualmente, como el segundo mayor exporta- 
dor per-cápita de América Latina y el cuarto país más competitivo de la región, según el Foro Económico Mundial 2011. (Schawab, 2011).

Esto no es totalmente nuevo porque Costa Rica construyó el epicentro de su desarrollo tradicional a partir de una temprana integración al mercado mundial, a través de lo que sería nuestro primer producto de exportación, el café. Con el grano de oro se abrieron para Costa Rica -y también para las economías centroamericanas, fundamentalmente agroexportadoras de monocultivo - las perspectivas que marcarían, desde entonces, lo que sería la vocación exportadora del país.

Esa vocación, esbozada desde los albores de nuestra vida independiente, cedió el paso a una visión regional que apostaba al desarrollo industrial bajo un esquema proteccionista. Fueron muchos los años perdidos que algunas economías asiáticas, que en los 50 eran muy semejantes a la nuestra, aprovecharon para crecer y que nosotros desperdiciamos, concentrados como estábamos, en el desarrollo regional de una zona marcada por la desigualdad, la inequidad y los límites que esas brechas generaban a la creación de un mercado interno.

Pero en 1985 retornamos a una política comercial "parcialmente" autónoma de Centroamérica y, desde entonces, la integración a la economía internacional es un eje central de nuestra política de desarrollo, que a lo largo de las últimas dos décadas ha promovido cambios significativos en nuestra estructura productiva. El punto de partida del exitoso mapa de ruta en la inserción del país al comercio internacional fue la histórica adhesión de Costa Rica al Acuerdo General de Aranceles Aduaneros y Comercio (GATT) en 1990. De ahí que, en 1995, aparece Costa Rica como Miembro originario de la OMC y, desde entonces, el país ha participado positivamente en el sistema multilateral de comercio.

Uno de sus principales logros ha sido la diversificación de su producción doméstica, mucha de la cual tiene mercados externos como objetivo. Costa Rica cuenta con más de cuatro mil productos en su oferta exportable, superando incluso a Chile, fenómeno que se explica por no basar su capacidad exportadora en industrias extractivas, sino en la atracción de inversiones extranjeras y en su participación en cadenas globales de valor. De ahí que las exportaciones de Costa Rica lleguen a un volumen acumulado que iguala la exportación agregada de todos los otros países centroamericanos.

Quien contempla hoy los resultados de Costa Rica en materia comercial, podría erróneamente deducir que ésta era una opción evidente en 1985 y dejar de apreciar que el peso de la globalización fue un fenómeno muy posterior a la decisión nacional de hacer de las exportaciones su principal motor de desarrollo. Relacionando este contraste, en mayo del 2010, a dos décadas de la inserción de Costa Rica en la OMC, la autora hace estas reflexiones, en un artículo de opinión, tomando como punto de partida las palabras de uno de sus impulsores, el expresidente Oscar Arias Sánchez:

Cuando don Óscar inició su primer mandato, parecía robusto el Muro de Berlín y el comercio globalizado era apenas leve brisa en el horizonte. Fue entonces que se optó por la inserción temprana y previsora de Costa Rica en el sistema multilateral de comercio. El comercio es fuerza ahora, no entonces. En aquellos días su decisión se adelantaba a los tiempos... En estas efemérides, es justo congraciarnos con las transformaciones de Costa Rica en el espacio de apenas dos décadas. De república bananera y cafetalera, nos convertimos en uno de los primeros países per cápita de América Latina en atracción de inversión extranjera encadenada con la producción nacional, con oferta exportable diversificada, múltiples destinos de exportación y fuentes de trabajo de alta calidad y buena remuneración (Govaere, 2010). 
Y, en verdad, en la globalización que vive el planeta, es casi inconcebible que un país se sustraiga al comercio mundial. Pero esa realidad de ahora no era evidente hace veinticinco años y el haberse colocado dentro de los signos de los tiempos, abriéndose al mundo de forma previsora, permitió que Costa Rica utilizara a fondo sus ventajas comparativas, en educación y en institucionalidad democrática y pacífica, para atraer inversiones, especialmente de alta tecnología y para estar preparada cuando, en 1995, se dio el punto de inflexión en el comercio mundial.

Lo primero fue abrirnos al mundo, desmontando el viejo sistema proteccionista tradicional de los años 60, creado en el marco del Mercado Común Centroamericano (MCC) y del paradigma fallido de sustitución de importaciones. Todavía con Centroamérica en medio de guerras civiles y con el MCC prácticamente paralizado, Costa Rica comenzó a redefinir unilateralmente su sistema arancelario. El arancel promedio de la década de los ochentas que era de un 52\%, en una economía regional proteccionista y cerrada, pasó a un $4 \%$ en nuestros días. Actualmente, el $64 \%$ de nuestro PIB está relacionado con el comercio, lo cual muestra el grado de apertura de nuestra economía (COMEX, 2011).

Desde los años 90, hemos negociado acuerdos comerciales con nuestros principales socios comerciales y hemos sido punta de lanza regional en el provechoso uso de los instrumentos preferenciales de acceso a mercados. De primera magnitud fue, en su momento, nuestro aprovechamiento, por ejemplo, del Sistema Generalizado de Preferencia y de la Iniciativa de la Cuenca del Caribe, que nos ha colocado a la vanguardia de los países regionales que exportan al mercado comunitario y estadounidense. El DR-CAFTA ("TLC con Estados Unidos") y el Acuerdo de Asociación con la Unión Europea vienen a consolidar una ruta ya trazada.
El camino recorrido por nuestro país hacia una sólida apertura comercial ha tenido como punta de lanza un proceso de acuerdos bilaterales, que han culminado con relaciones preferenciales con nuestros principales socios comerciales. Entre ellos destacan la misma Centroamérica, que tuvo que redefinir su integración hacia afuera; los Estados Unidos que evolucionaron desde concesiones unilaterales hasta un acuerdo regional y la Unión Europea, que también está en el proceso de evolución de su sistema de preferencias hacia un Acuerdo de Asociación que todavía no termina de ser aprobado ni por la Comisión Europea ni por nuestra Asamblea Legislativa.

Capítulo especial ocupa nuestra relación comercial con China, mercado que sorpresivamente se convirtió, desde 2006, en nuestro segundo destino de exportación, básicamente por la producción de INTEL-COSTA RICA. A pesar de tener una extremadamente concentrada base exportadora, el peso de nuestras exportaciones al gigante asiático señaló la oportunidad que se abría a nuestra inserción en Asia, movimiento decisivo que acompaña también y precede, como en 1985, a una tendencia internacional marcada, de dominio económico internacional de los países del pacífico asiático. El TLC con China, con Singapur, las negociaciones ya previstas con Corea del Sur, y las también previsibles con Japón y con India, junto con la solicitud planteada de ingresar a APEC, perfilan los siguientes pasos de la estrategia comercial de Costa Rica.

La incidencia de los 25 años de apertura comercial ha tenido impacto directo en el desarrollo socio-económico del país con la consecuente transformación productiva del país. Los frutos de una política de apertura exitosa se reflejan en el desempeño de un sector productivo que ha visto crecer sus exportaciones y diversificar su oferta, con creciente valor agregado hacia una gama amplia de destinos, construyendo una plataforma 
exportadora que se ha vinculado positivamente con la inversión extranjera directa (IED).

Esta es una mirada panorámica de esos índices de desempeño que nos colocan como mejor práctica, pero a la vez, al mirar los logros de una política comercial exitosa, se acompaña de la interrogante que pende sobre las necesidades de acompañamiento a la apertura comercial con políticas públicas integrales, que no se dieron en esas dos décadas, tanto a nivel de productividad y competitividad internas, como de acceso social a las oportunidades abiertas por el comercio y de adecuación del aparato estatal a un mundo que exige mayor inversión pública y mejor eficiencia administrativa.

Este artículo forma parte del proyecto de investigación "La incidencia de 25 años de apertura comercial en el modelo de desarrollo socio-económico de Costa Rica" de OCEX-UNED y representa un aporte de la visión integral y holística de la academia costarricense a este proceso.

\section{Un largo pero exitoso recorrido}

Desde hace 25 años, Costa Rica ha centrado su desarrollo en la apertura comercial y su estrategia política de aprovechamiento del comercio se puede considerar, probablemente, una de las más exitosas y complejas de la región latinoamericana. La escasa flexibilidad de nuestra economía fue puesta en evidencia en la crisis de los década de los ochenta del siglo pasado y marca el pivote de nuestra inserción al comercio internacional, tal y como lo indica Herrera:

... se han venido introduciendo una serie de medidas de ajuste en la conducción de la política económica, orientadas a mejorar la eficiencia y la competitividad de nuestras actividades productivas, con la idea de aprovechar al máximo las oportunidades que ofrece el mercado internacional para imprimir un mayor dinamismo a la economía nacional. En efecto, las fuentes tradicionales de crecimiento de la economía costarricense, que estuvieron constituidas en el pasado por las exportaciones tradicionales, el mercado común centroamericano y el mercado interno; no ofrecían la posibilidad de alcanzar el dinamismo que requiere la economía del país para atender sus necesidades, sus compromisos internacionales y menos aún para elevar el nivel de bienestar de la población (Herrera, 1990).

En 1986, nace a la vida jurídica e institucional, el Ministerio de Comercio Exterior (COMEX). COMEX se estableció en el primer año de la Administración Arias y como acción prioritaria del recién creado Ministerio, se le otorgó competencia para promover exportaciones, apoyar al régimen de exportaciones de zona franca y liderar nuestra inserción al Acuerdo General de Aranceles y Comercio (GATT). Esta fue la piedra angular de una larga trayectoria de apertura comercial, que dentro de sus ejes principales establece como prioridad nacional:

Dentro de la estrategia de desarrollo con que se ha comprometido este Gobierno la promoción de exportaciones tiene un carácter vital. Estas no sólo son el vehículo para generar divisas sino que bajo el enfoque "Exportaciones para el Desarrollo", se les concibe como el elemento motor que impulsará el desarrollo durante las próximas décadas y que constituirá la piedra angular del desarrollo del cambio estructural de la economía costarricense (COMEX, 1987).

El proceso de reducción de aranceles que el país había emprendido de forma unilateral se vinculó con nuestra decisión de ingresar al sistema multilateral de comercio. Como indica el entonces coordinador de "Asuntos GATT" del Ministerio de Comercio Exterior, Carlos Herrera Amighetti, "La incorporación de Costa Rica al GATT constituye un elemento de gran utilidad para llevar 
para adelante la estrategia de desarrollo del país, orientada a crear un sector exportador dinámico y eficiente, capaz de competir en los mercados internacionales" (Herrera, 1990). La activa participación de Costa Rica como país observador en la Ronda Uruguay fue entrenamiento efectivo de nuestros primeros equipos comerciales y culminó con la adhesión de nuestro país al Acuerdo General de Aranceles Aduaneros y Comercio en 1990, siendo Costa Rica la parte contratante número cien del GATT.

Nuestra adhesión al GATT (1990) y luego a la OMC (1995) fue el primer gran paso en nuestra apertura comercial, que cobijaba nuestra aspiración de insertarnos positivamente al comercio internacional y de incrementar nuestras exportaciones al mundo. La promoción de exportaciones es pues, el primer pilar de las tres grandes directrices que han guiado, a lo largo de más de 2 décadas, la construcción de nuestro actual modelo de desarrollo: apertura de mercados a través del crecimiento de nuestras exportaciones; la búsqueda de una oferta sostenible debidamente diversificada y la atracción de una inversión extranjera de calidad, que debería eventualmente poder encadenarse a nuestro tejido productivo.

Obviamente, en el proceso de incursión de Costa Rica al mundo y como consecuencia de un crecimiento importante en las exportaciones del país, se diseñaron una serie de ajustes considerados necesarios, en materia comercial. Este crecimiento de exportaciones, que se acelera en la década de los noventa, se vincula al fomento de la Inversión Extranjera Directa.

En el transcurso de la década de los años noventa, la economía atravesó un importante proceso de transformación, en muchos casos asociada al papel creciente que adquirió el comercio exterior. La economía creció a un promedio elevado del 5.4\% durante la década, impulsada en gran medida por las ex- portaciones que se cuadruplicaron (...). Este fuerte incremento puede atribuirse a dos factores principales: por una parte, al proceso de apertura comercial y reducción arancelaria que se desarrolló desde el comienzo de la década y, por la otra, a un importante flujo de Inversiones Extranjeras Directas (IED) producido hacia finales de la década en las zonas francas de exportación, principalmente en las industrias de alta tecnología y de alto valor agregado (BID-INTAL, 2007).

Cuando se gestó nuestra apertura al mundo, nuestra economía dependía básicamente de dos productos agrícolas: café y banano. Con la crisis de los ochenta del siglo pasado, Costa Rica comprendió la importancia de diversificar su oferta exportable, para disminuir su dependencia de unos cuantos productos tradicionales. El giro de los ochentas repercutió, tan pronto como en 1992, en una agresiva ampliación de nuestra oferta exportable, como lo señaló en su momento el entonces Ministro de Comercio Exterior, Roberto Rojas:

La evolución de las exportaciones de productos no tradicionales muestra que siguen creciendo en importancia, este año con una tasa de crecimiento anual del 23\% (jSIC! -la autora) para un monto total de 1.080 millones de dólares, hecho que corrobora una vez más el éxito que sigue teniendo la política de promoción de exportaciones con la diversificación cada vez mayor de nuestra oferta exportable. Destacan por su importancia relativa dentro de las exportaciones de productos no tradicionales la piña, las prendas de vestir, los medicamentos, las plantas, el follaje, los productos marinos y el melón (COMEX, 1992).

Es importante destacar que la ofensiva exportadora de aprovechar al máximo las oportunidades generadas por mecanismos unilaterales de preferencias, como la Iniciativa de la Cuenca del Caribe 
(mercado estadounidense) y el Sistema Generalizado de Preferencias Régimen Droga (mercado comunitario) fueron instrumentos fundamentales en nuestro crecimiento exportador.

De forma simultánea a un exitoso desempeño de estos instrumentos, cabe destacar el crecimiento de nuestras exportaciones bajo regímenes especiales de exportación. La memoria del año 1992 también destaca

...la importancia que han tenido para la generación de estos nuevos productos exportables, los diversos regímenes de promoción a las exportaciones existentes. El componente correspondiente a las exportaciones de los regímenes de admisión temporal y zonas francas creció durante 1992 a una tasa del $16 \%$... el número de empresas establecidas en un 27\%, generando alrededor de 13.000 empleos e inversiones mayores de los 300 millones de dólares en el país (COMEX, 1992).

La década de los noventa del siglo pasado tiene como sello el inicio de las negociaciones bilaterales y la redefinición orgánica y normativa del Mercado Común Centroamericano, como una integración hacia afuera. El Mercado Común Centroamericano, suscrito en la década de los sesenta, retoma vigor en los noventa y se perfila, desde el 2007, como una Unión Aduanera. Costa Rica ha reconocido la relevancia del fortalecimiento de los lazos regionales, comprendiendo que una Unión Aduanera compensa nuestras pequeñas economías centroamericanas con un esquema subregional que genera beneficios de economías de escala convirtiendo, todavía sólo potencialmente, a la región en una sola zona de negocios.

El sello distintivo de la política comercial costarricense es el pragmatismo. Costa Rica se ha unido a Centroamérica, en negociaciones regionales con Estados Unidos o la Unión Europea, y al mismo tiempo, cuando ha sido posible y deseable, ha combinado su estrategia centroamericana con negociaciones bilaterales, concretando acuer- dos comerciales con países como Chile, Canadá, Panamá o el CARICOM y ahora China. Así, desde la génesis de este proceso, los esfuerzos costarricenses por fortalecer los lazos comunitarios centroamericanos, en los que Costa Rica participó con entusiasmo, siendo sede inclusive en el Pacto de San José, fueron siempre combinados con políticas de apertura comercial agresiva y bilateral, fuera del componente centroamericano.

El Tratado de Libre Comercio con México, negociado de forma bilateral por Costa Rica, entra en vigencia en 1995, de forma paralela con nuestra adhesión a la Organización Mundial del Comercio. Se visualiza que, fuera de la OMC, y a lo largo de la década de los 90 y la primera década del siglo XXI hemos gestado una plataforma de acuerdos comerciales con nuestros socios comerciales más relevantes.

Como resultado, Costa Rica ha construido una sólida plataforma comercial que incluye tratados bilaterales o multilaterales con Estados Unidos, Canadá, México, los países centroamericanos, Panamá, las naciones del Caribe, Chile y China. Los tratados de libre comercio que tenemos con Estados Unidos, con China y con 13 países más, y los que acabamos de negociar con Singapur, Perú y la Unión Europea, ampliarán la cobertura con tratamiento preferencial en 52 países representando más del 83\% de las exportaciones costarricenses y ese amplio acceso internacional asegura economías de escala para Costa Rica. (Chan, 2012). Actualmente se está a la espera de la ratificación de acuerdos con Singapur, Perú y la Unión Europea, y esperamos iniciar próximamente negociaciones con Corea del Sur.

La llegada de Intel a Costa Rica, durante la Administración Figueres, marca una inflexión hacia la producción masiva de bienes de alta tecnología y señala el inicio de lo que es hoy, actualmente, una de nuestras más relevantes "cadenas globales de valor". Intel, a lo largo de más de 13 años, ha incrementado su inversión a más de 800 
millones de dólares, ofreciendo más de 3000 empleos de calidad y representando el $20 \%$ de todas las exportaciones costarricenses (ChinchiIla, 2011). Ese peso colosal de una sola empresa, puede distorsionar la visión precisa del estado de la economía nacional. Por eso existe un concepto de análisis, coloquialmente aceptado en el sector de comercio exterior costarricense, que resume el impacto -y la posible distorsión- del peso de Intel en nuestro país: "hay que contabilizar la balanza comercial, con o sin Intel".

La diversificación de nuestra oferta exportadora es producto de múltiples factores entrelazados dentro de nuestra apertura comercial, como el auge de las empresas instaladas en Zona Franca, la diversificación tecnológica en la agricultura y también, significativamente, la llegada de la primera gran empresa de alta tecnología instalada en el país, como componente decisivo del punto de inflexión de nuestra participación en las cadenas globales de valor.

Según reflexión del estudio del BID:

Otro factor que ha sido preponderante en la diversificación de la canasta exportadora ha sido el modelo de promoción de exportaciones que se implementó a partir de 1984. Uno de los elementos característicos de este modelo es el régimen de ZF. Las empresas acogidas a él han representado una proporción marcadamente creciente de las exportaciones totales durante los últimos años, pasando de 10 por ciento en 1992 a 20 porciento en 1997. En 2000, tras la llegada de INTEL, las exportaciones de las empresas instaladas en ZF superan el 50 por ciento de las exportaciones totales (Rodríguez-Clare, 2003).

Como se analizará en detalle posteriormente, el país ha logrado consolidarse a lo largo de estas décadas como actor relevante en la arena internacional de las cadenas globales de valor, en particular la correspondiente a componentes electrónicos. El país, bajo el liderazgo de CINDE, ha logrado un posicionamiento relevante como país receptor de inversión en componentes electrónicos, dispositivos médicos y servicios, con una alta afluencia de empresas multinacionales que se instalan en suelo costarricense.

Como indica la autora:

... la IED está ligada a la generación de empleos, al incremento de la producción, a la transferencia de tecnología y al potencial de crear, además, encadenamientos productivos con las empresas locales, especialmente la pequeña y mediana empresa costarricense. Este eje se vincula con el esfuerzo nacional de hacer de Costa Rica una plataforma para que los productos producidos en el país tengan acceso preferencial a los mercados de nuestros principales socios comerciales, en condiciones privilegiadas, porque nadie invertiría en un país que no ofrezca salida a sus productos (Govaere, 2011).

Este elemento de nuestra política comercial ha sido sumamente exitoso. Sin embargo, no deben asumirse como automáticos los beneficios de la inversión extranjera directa, ya que deben estar debidamente complementados con un componente interno de educación, entrenamiento laboral, facilitación de encadenamientos, entorno de negocios competitivo, entre otros factores.

Veinticinco años de apertura comercial marcan la transición de una economía que apostaba al monocultivo exportador y a la sustitución de importaciones, a una economía diversificada, con alto valor agregado y con acceso preferencial asegurado a los mercados de sus socios preferenciales. La apertura comercial que generó el incremento de nuestras exportaciones y la diversificación de nuestra oferta al mundo se articuló con una política de atracción de inversión extranjera directa especialmente de alta tecnología, dispositivos médicos y de servicios, para asegurar al país la oferta de empleos de calidad. 
Hoy, el comercio exterior de mercancías representa un 64\% del PIB (COMEX, 2010), constituyendo el motor de crecimiento de nuestra economía al generar nuevas oportunidades para el sector productivo, más empleos y mayor calidad de vida.

\section{Principales índices de desempeño del comercio exterior}

Con sólo 4 millones y medio de habitantes, ya desde el 2009, aproximadamente 400.000 costarricenses trabajan en las más de 2000 empresas que venden 4116 productos a 135 países en el mundo, por un valor de $\$ 8.675$ millones. (Ocampo, 2011). Exportamos desde frutas tropicales pasando por chips para computadora hasta válvulas para el corazón. Somos el primer exportador per cápita de bienes en América Latina, excluyendo minerales y combustibles, y el cuarto país del mundo entre aquellos con mayor proporción de exportaciones de alta tecnología dentro de sus exportaciones industriales.

\section{Crecimiento de exportaciones}

La década de los setenta trajo consigo el final de la era del modelo de sustitución de importaciones, que había prevalecido hasta entonces. Uno de los elementos que impactaron fuertemente en la economía de Costa Rica, al final de los años setentas, fue la disminución en los precios de los escasos productos agrícolas tradicionalmente exportados por Costa Rica. La concentración de nuestra oferta se vinculó a problemas estructurales en la economía costarricense, conduciendo al país por el conocido camino del endeudamiento externo para soslayar el desequilibrio de las finanzas públicas. Como señala Villasuso:

Durante muchos años el déficit crónico de la balanza comercial de Costa Rica no fue obstáculo para el crecimiento de la producción nacional, ya que el ahorro externo, en forma de endeudamiento público o inversión ex- tranjera siempre estuvo disponible en los montos requeridos. Cuando sobrevino el segundo shock petrolero, y poco después la recesión en los países industriales y la caída en los precios de los principales productos de exportación nacionales, estos fenómenos se adicionaron a los problemas estructurales que padecía la economía costarricense, provocando cambios de gran magnitud en la dimensión comercial y financiera del país. Se recurrió entonces al endeudamiento externo para atender la ampliación del déficit comercial y para financiar el desequilibrio de las finanzas públicas, que había ido acumulándose como resultado del crecimiento del Estado sin la correspondiente contrapartida por el lado de los ingresos (Villasuso, 1999).

Entre 1980 y 1982 el PIB disminuyó casi un 10\% y la producción nacional se redujo, produciendo que el ingreso nacional disminuyera en un 22\%, esto produjo que el ingreso per cápita se contrajera más de una cuarta parte, en círculo vicioso (Villasuso, 1999).

A mediados de la década de los ochenta, el país toma la decisión de iniciar la transición del modelo de sustitución de importaciones hacia un modelo de desarrollo que tiende hacia la promoción de las exportaciones, estrategia basada en la apertura comercial.

Adicionalmente, los Estados Unidos y la Unión Europea tuvieron gran influencia en el aprovechamiento del nuevo diseño de esta política comercial "hacia afuera", por medio de la Iniciativa para la Cuenca del Caribe (ICC) y del Sistema Generalizado de Preferencias (SGP), que permite el acceso a ambos mercados en condiciones arancelarias preferenciales, lo que aumentó la competitividad de los productos costarricenses en esos mercados.

Las herramientas de política comercial implementados a nivel multilateral, regional y bilateral dieron fruto. La Política de Estado de más de dos 
décadas, han resultado, como se dijimos supra, en un crecimiento significativo en nuestras exportaciones. Bajo la consigna de "Exportaciones para el Desarrollo", se concibió el incremento de exportaciones como el motor del desarrollo costarricense y la piedra angular de un urgente cambio estructural en nuestra economía.

Como se muestra en la tabla 1, nuestras exportaciones han crecido de forma sostenible.

TABLA 1

\section{EXPORTACIONES TOTALES DE COSTA RICA 1985 - 2010}

\begin{tabular}{|c|c|c|}
\hline Año & $\begin{array}{c}\text { Exportaciones } \\
\text { (Millones US\$) }\end{array}$ & $\begin{array}{c}\text { Tasa interanual } \\
\text { de crecimiento } \\
(\%)\end{array}$ \\
\hline 1985 & 1081,6 & $-3,8 \%$ \\
\hline 1986 & 1233,0 & $14,0 \%$ \\
\hline 1987 & 1302,3 & $5,6 \%$ \\
\hline 1988 & 1448,7 & $11,2 \%$ \\
\hline 1989 & 1694,1 & $16,9 \%$ \\
\hline 1990 & 1768,0 & $4,4 \%$ \\
\hline 1991 & 1899,3 & $7,4 \%$ \\
\hline 1992 & 2385,2 & $25,6 \%$ \\
\hline 1993 & 2625,5 & $10,1 \%$ \\
\hline 1994 & 2596,6 & $-1,1 \%$ \\
\hline 1995 & 3190,1 & $22,9 \%$ \\
\hline 1996 & 3681,2 & $15,4 \%$ \\
\hline 1997 & 4189,9 & $13,8 \%$ \\
\hline 1998 & 5478,6 & $30,8 \%$ \\
\hline 1999 & 6707,9 & $22,4 \%$ \\
\hline 2000 & 5897,3 & $-12,1 \%$ \\
\hline 2001 & 5042,8 & $-14,5 \%$ \\
\hline 2002 & 5280,5 & $4,7 \%$ \\
\hline 2003 & 6100,2 & $15,5 \%$ \\
\hline 2004 & 6279,3 & $2,9 \%$ \\
\hline 2005 & 7000,6 & $11,5 \%$ \\
\hline 2006 & 8198,2 & $17,1 \%$ \\
\hline 2007 & 9343,2 & $14,0 \%$ \\
\hline 2008 & 9552,8 & $2,2 \%$ \\
\hline 2009 & 8611,3 & $-9,9 \%$ \\
\hline $2010^{*}$ & 9370,7 & $8,8 \%$ \\
\hline
\end{tabular}

Fuente: COMEX con cifras del BCCRy PROCOMER.

Nota: Incluye el valor de las exportaciones de zona franca y del régimen de perfeccionamiento de activo.
La composición de nuestras exportaciones de los últimos años, en términos de sectores productivos, traduce el fuerte crecimiento de nuestro sector servicios, de nuestro sector industrial y también, pero en menor medida, de nuestro sector agrícola. El crecimiento de nuestras exportaciones, la diversificación de destinos, la atracción de IED y su consecuente encadenamiento doméstico son factores relevantes en el cambio de la composición de nuestro tejido productivo, como se muestra en la figura 1.

\section{FIGURA 1 \\ EXPORTACIONES DE COSTA RICA, SEGÚN SECTOR ECONÓMICO (EN MILLONES DE DÓLARES, AGRUPADO DE 1998 AL ESTIMADO DEL 2014)}

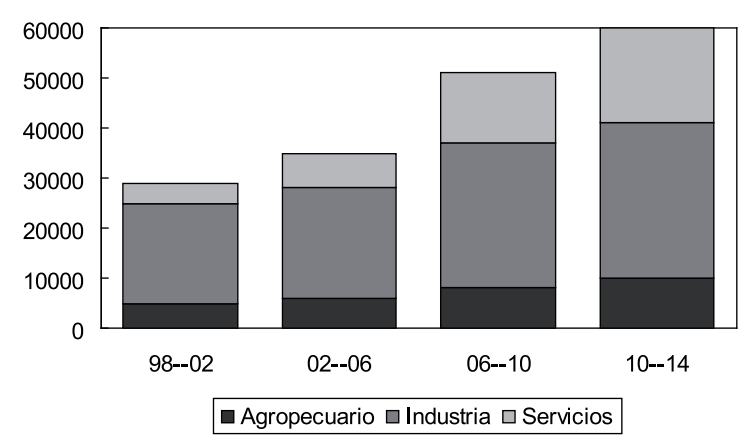

Fuente: COMEX.

Estados Unidos se mantiene como nuestro principal destino de exportación. Desde el año 2006, el segundo lugar se alterna entre el mercado asiático de China continental y el mercado comunitario. En cuarto lugar se encuentra el comercio regional.

Sin embargo, con todos los resultados positivos de las últimas décadas, en términos de un comportamiento generalmente positivo de nuestras exportaciones, de importante diversificación de destinos, y una extraordinaria diversificación de nuestra oferta productiva, nuestra balanza comercial es negativa de forma crónica, como se puede apreciar en la figura 2. 
FIGURA 2

\section{BALANZA COMERCIAL DE COSTA RICA (DE 1985 A 2010, EN MILLONES DE DÓLARES)}

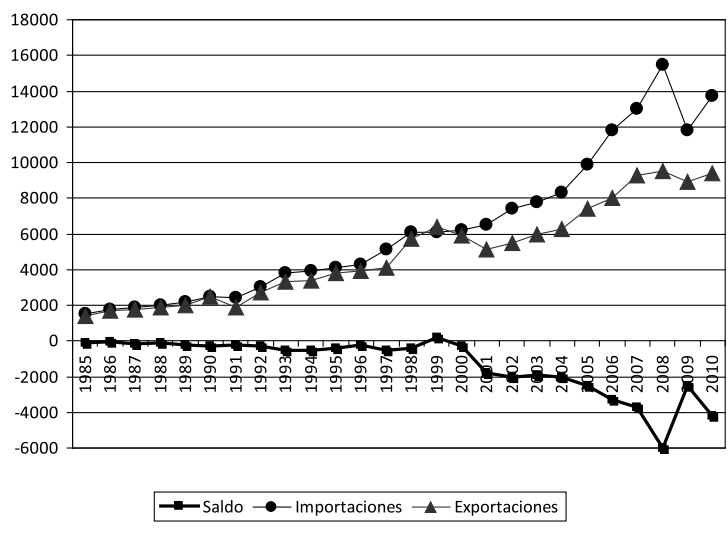

Fuente: $B C C R$

Nota: Ios datos del 2010 son preliminares

Esta problemática será abordada posteriormente en las conclusiones como uno de los desafíos más importantes para el país.

\section{Entre el valor total exportado y la diversificación de la demanda: contraste de impactos de los destinos de exportación}

Hemos enfatizado el resultado de pasar de una exportación de pocos productos tradicionales agrícolas, como fueron el café y el banano, sólo hace algunas décadas, a exportar más de 4.000 productos a 146 países en el mundo, con la oferta más diversificada de Latinoamérica. (COMEX, 2011).También se ha enfatizado el crecimiento del valor total de las exportaciones. Ambos elementos no son necesariamente correlativos y el impacto que tiene para Costa Rica, en su sector productivo y social, un mercado diversificado, aunque de menor valor total de exportaciones, es de una relevancia social y económica más grande que un mercado de alto valor de expor- taciones, pero de poca diversificación de su demanda de productos nacionales.

Se puede fácilmente ilustrar la correlación que existe en los impactos productivos y sociales nacionales de las demanda -ampliada o concentrada- de nuestros productos, ambas situaciones en condiciones preferenciales. Aunque ambas situaciones son resultado concomitante a nuestra apertura comercial, su efecto en la vida socioeconómica nacional es diferente.

Dos ejemplos pueden ilustrar esto.

Cuando en el año 2006, China se convirtió, sorpresivamente para muchos, en el segundo destino de exportación de Costa Rica, la comunidad empresarial costarricense no visualizó como de gran impacto dicho logro, dentro del contexto de su oferta exportable, ya que ese destino estaba concentrado en dos o tres productos y aunque beneficiaba grandemente nuestro balance comercial y nuestras cuentas nacionales, tenía un impacto casi nulo en la dinámica empresarial.

Esa segunda posición como mercado exportador, lograda en los años 2006 y 2007, responde a una demanda sumamente concentrada en dos productos de exportación de alto valor tecnológico. Datos del 2009 mostraban que nuestra oferta a China se concentraba en un $96 \%$ en microprocesadores (INTEL), productos electrónicos y piezas de computadora. Esto se podría prácticamente traducir con las palabras "exportaciones INTEL".

Por ello, el examen de las exportaciones hacia un socio comercial, deben ir más allá del mero valor de la exportación a ese destino, e incluir en el análisis la composición de su oferta.

La caída de la demanda de estos productos en China, resultado de la prolongación de la crisis del año 2008, marcan una caída importante de nuestras exportaciones a dicho mercado, con un fuerte peso en nuestras cuentas públicas, pero 
con poco impacto en la economía, como un todo. Eso confirma que una fuerte concentración de la oferta restringe las oportunidades que genera un mercado a nuestro tejido productivo. Eso, por otra parte, es de alguna manera, un recordatorio en otras condiciones, de la lección de los años ochenta, de una oferta concentrada que no resiste, por esa misma condición, los embates de condiciones externas negativas.

Si comparamos la oferta costarricense dirigida a este mercado asiático con nuestra diversificada oferta al mercado comunitario de la Unión Europea, vemos el rédito que genera una oferta amplia. Las exportaciones costarricenses al mercado comunitario, precisamente en el 2006, cuando fue desplazado por China, como segundo destino, superaban los 500 productos, con un impacto potencial en más de 1500 empresas, industriales y agrícolas, a lo largo y ancho del territorio nacional, e impactos indirectos mucho más diversificados, sectorial y territorialmente.

Esa diversificación de productos de exportación es uno de los aspectos más relevantes de nuestra oferta al mercado comunitario, donde la oferta agrícola se combina con una exportación de productos cuyos principales componentes tienen valor agregado, al menos un tercio de los cuales, con alto valor tecnológico.

Mientras el resto de la región centroamericana sigue recibiendo 1 de cada 3 dólares por las exportaciones de café al mercado comunitario, para Costa Rica el café es solamente el quinto producto de exportación a ese mercado. En cambio, las exportaciones con alto contenido tecnológico -ligados obviamente a la IED-representaban más del 40\% en concepto de ingresos percibidos de las ventas al mercado comunitariom (Govaere, 2009). Todavía productos agrícolas como el café, el banano y la piña costarricenses tienen una fuerte aceptación en el mercado comunitario, contamos con una amplia y diversificada oferta de manufactura y de componentes de la cadena global de valor a dicho destino.

Al tiempo que el mercado chino apenas se recupera, el mercado comunitario, afectado claramente por la crisis del euro, se ha incrementado ya a casi 600 productos, representando, en valor, aproximadamente el 20\% de nuestra oferta exportable al mundo. Pero, como queda visto, su impacto socioeconómico va más allá de las divisas que se generan en uno o en otro.

Esta comparación entre dos mercados que se reparten el segundo puesto como destino de las exportaciones costarricenses, resalta el impacto de un mercado más allá de los valores de exportación que genere.

El peso dinamizador de un destino exportador se mide por la amplitud de su demanda, el número de empresas que accede a ese mercado, el volumen de encadenamientos que produce y la población beneficiada, objetivo final de toda política pública. El impacto de la demanda china podrá, de nuevo, llegar a superar a la comunitaria, pero su impacto socioeconómico será menor mientras se limite a pocas empresas, con menor generación de empleo y encadenamientos productivos. La demanda de la UE tiene mayor huella territorial en regiones de mayor pobreza, si se contrapone con las empresas de alta tecnología que promueven transferencia tecnológica y dinamismo macroeconómico, pero están concentradas en la GAM (Govaere, 2010).

Sin menoscabo de la importancia de China como destino de nuestras exportaciones, incluso en el clima de incertidumbre económico actual, una oferta diversificada, como los 600 productos destinados al mercado comunitario, además de su mayor impacto socioeconómico local, tiene por otra parte características de mayor "resiliencia" frente a los escenarios adversos de estos próximos años. 
"Una vez que entre en vigencia el Acuerdo de Asociación entre Centroamérica y la Unión Europea, las exportaciones nacionales dejarían de pagar poco más de $\$ 240$ millones en impuestos. Este monto lo cancelan, entre otros, productos y bienes que no están contemplados dentro del Sistema General de Preferencias Arancelarias (SGP-Plus)" (Karel De Gucht, citado por Barquero, 2011). Indica el Comisario que, de los países centroamericanos, Costa Rica es el país que más aprovecha la relación comercial con el mercado comunitario señalando que nuestro país "es el principal socio comercial de la Unión Europea, en Centroamérica. Solo el año pasado, el país obtuvo ingresos por \$1.668 millones en exportaciones al Viejo Continente" (Karel De Gucht, citado por Barquero, 2011).

\section{Un desempeño positivo en la atracción de IED}

La solidez y estabilidad de nuestro sistema democrático, el respeto por el Estado de Derecho y una sólida institucionalidad, así como la calidad y facilidad de entrenamiento de nuestra fuerza laboral, son parte de las ventajas comparativas que nos hacen un destino atractivo para la Inversión Extranjera Directa. Una ubicación geográfica privilegiada y una robusta plataforma exportadora que asegura acceso preferencial a los mercados más importantes del planeta promueven un ambiente que ha probado, sin lugar a dudas, ser altamente atractivo para la inversión extranjera.

Así, mientras en la década que precedió la crisis de los 80 , el recurso a la deuda pública fue la insostenible manera de compensar el constante déficit de nuestra balanza comercial, en la actualidad nuestras mayoritarias importaciones se ven compensadas por una fuente mucho más sana de ingreso de divisas: la inversión extranjera directa. Por eso, la IED tiene un impacto directo en nuestra balanza de pagos y ocupa, más allá de las cuentas nacionales, un papel fundamental, particularmente en lo que atañe a la promoción del crecimiento económico, la generación de empleo de calidad para nuestra gente, oportunidades de encadenamiento con el tejido productivo nacional, aumento y diversificación de nuestra oferta exportable, mejoramiento de la participación de Costa Rica en las cadenas globales de valor y, último en mencionar, pero tal vez de mayor importancia, transferencia tecnológica y creación de capacidades de nuestro recurso humano en las mejores prácticas industriales y gerenciales.

\section{Una consistente política pública}

Desde mediados de la década de los ochenta, Costa Rica ha adoptado una consistente política que basa su desarrollo en dos grandes ejes: apertura de nuevos mercados, para la construcción de una plataforma exportadora y, engarzada en esa plataforma exportadora, la atracción de inversión extranjera directa.

... desde mediados de la década de los ochenta el país ha experimentado flujos crecientes de IED, como resultado en buena parte del proceso de apertura económica iniciada en esos años, el mayor acceso de los productos costarricenses al mercado de los EEUU, gracias a la Iniciativa de la Cuenca del Caribe (ICC), así como a la disponibilidad de mano de obra calificada y a los esfuerzos de atracción de inversión extranjera por parte de la Coalición Costarricense de Iniciativas de Desarrollo (CINDE), en coordinación con las autoridades del país (Monge, 2001). Otros factores como la estabilidad política y económica, así como los beneficios asociados al Régimen de Zonas Francas, han sido también elementos favorables (Monge, 2005).

Políticas de atracción de inversiones, bajo la dirección de CINDE, empezaron a recabar impor- 
tantes logros en la década de los 90, especialmente con la llegada de INTEL a Costa Rica, hace ya 13 años. "... a partir de la segunda mitad de los años noventa es cuando el país registra la mayor afluencia de IED, especialmente de empresas con un mayor contenido tecnológico y negocios relativos a servicios internacionales como centros de oficina y llamadas" (Monge, 2005).

Como resultado de una consistente política de largo plazo, Costa Rica ha logrado atraer flujos crecientes y acelerados de inversión. Así, mientras en el período 1991-1995, Costa Rica atrajo un total de US\$1.286 millones, para un promedio anual de \$257 millones; sólo en el año 2010, la IED ascendió a US\$1.466 millones. La IED de Costa Rica ha crecido en promedio 12\% cada año desde 1990 - y salvo una caída del 34\% en el 2009, ha tenido siempre un incremento positivo. Posterior al 2009, y todavía en medio de una difícil recuperación económica, hubo una fuerte recuperación en el 2010 y el 2011 (González \& Ocampo, 2011).

La presente Administración definió metas de inversión extranjera directa (IED) y de exportación para el periodo 2010-2014. Para esta administración la meta fijada para la IED acumulada en estos cuatro años es de US\$ 8.900 millones. A pesar de las dificultades económicas internacionales, la IED captada por Costa Rica en el 2010 fue de 1.466 millones de dólares (COMEX, 2010). Siguiendo ese comportamiento positivo y resultado de acciones pertinentes para la captación de IED, ya para los primeros seis meses del 2011, la inversión extranjera directa alcanzó un 45\% más que el valor registrado para el mismo periodo en el año pasado, lo que representa en concepto de IED para el primer semestre de 2011 la suma de US\$1.057 millones, que es el equivalente al $57 \%$ de la meta de inversión fijada para 2011 (COMEX, 2011).
Como se podrá visualizar en la tabla 2, el posicionamiento de Costa Rica como destino de la IED ha sido una apuesta exitosa.

TABLA 2

\section{COSTA RICA: INVERSIÓN EXTRANJERA DIRECTA 1985 - 2010}

\begin{tabular}{|c|c|c|}
\hline Año & IED millones US\$ & $\begin{array}{c}\text { Tasa } \\
\text { de crecimiento }\end{array}$ \\
\hline 1985 & 69,8 & $25,1 \%$ \\
\hline 1986 & 60,9 & $-12,8 \%$ \\
\hline 1987 & 94,0 & $54,4 \%$ \\
\hline 1988 & 123,1 & $31,0 \%$ \\
\hline 1989 & 101,2 & $-17,8 \%$ \\
\hline 1990 & 162,4 & $60,5 \%$ \\
\hline 1991 & 178,4 & $9,9 \%$ \\
\hline 1992 & 226,0 & $26,7 \%$ \\
\hline 1993 & 246,7 & $9,2 \%$ \\
\hline 1994 & 297,6 & $20,6 \%$ \\
\hline 1995 & 336,9 & $13,2 \%$ \\
\hline 1996 & 426,9 & $26,7 \%$ \\
\hline 1997 & 406,9 & $-4,7 \%$ \\
\hline 1998 & 611,7 & $50,3 \%$ \\
\hline 1999 & 619,5 & $1,3 \%$ \\
\hline 2000 & 408,6 & $-34,0 \%$ \\
\hline 2001 & 460,4 & $12,7 \%$ \\
\hline 2002 & 659,4 & $43,2 \%$ \\
\hline 2003 & 575,1 & $-12,8 \%$ \\
\hline 2004 & 793,8 & $38,0 \%$ \\
\hline 2005 & 861,0 & $8,5 \%$ \\
\hline 2006 & 1469,1 & $70,6 \%$ \\
\hline 2007 & 1896,1 & $29,1 \%$ \\
\hline 2008 & 2078,2 & $9,6 \%$ \\
\hline 2009 & 1346,5 & $-35,2 \%$ \\
\hline $2010^{*}$ & 1465,6 & $8,8 \%$ \\
\hline
\end{tabular}

Fuente: COMEX con base en cifras de $B C C R$.

* Las cifras de 2010 son preliminares. 
Impacto de la IED

en nuestro tejido productivo

Como veremos en acápites posteriores, la IED está estrechamente ligada con la cada vez más relevante participación de Costa Rica en las principales cadenas globales de valor del mundo y, además, con el encadenamiento doméstico de esta inversión con nuestro sector productivo, especialmente a través del régimen de zona franca. Esto tiene el potencial de generar, como se ha indicado, un "derrame" en términos locales de encadenamiento con la mediana y pequeña empresa nacional y una excelente oferta laboral, que más allá de la mera generación de empleo, crea capacidades en nuestro fuerza laboral y transfiere tecnología.

Las acciones gubernamentales tendientes a la atracción de IED también han sido, desde ya más de una década, fuertemente focalizadas a sectores que han sido considerados estratégicos para el desarrollo nacional. Estos tres sectores han sido fortalecidos con la recepción de empresas multinacionales en segmentos como servicios, componentes electrónicos y dispositivos médicos, lo que ha tenido como resultado un cambio notable en el rostro diversificado de nuestro tejido productivo nacional. Empresas como Intel, Hewlett Packard, Procter and Gamble o la recién captada inversión de Hospira (dispositivos médicos, 2011) son sólo algunas de las emblemáticas compañías multinacionales que han invertido en el país.

Como se ha indicado previamente, nuestra política de atracción de la Inversión Extranjera combinada con regímenes de exportación como zona franca, ha tenido un impacto directo en nuestra participación en las cadenas globales de valor, como es el caso en la producción de componentes electrónicos de alto valor agregado, que demandan recurso humano especializado y que, a su vez, generan en nuestro país una demanda de empleos de calidad, bien remunerados, así como permiten, además, la creación de capacidades para el empoderamiento de una amplia diversificación de transferencias de tecnologías.

La IED ha sido la clave para la transformación que ha tenido Costa Rica desde actividades sencillas hacia actividades que utilizan más tecnología y recurso humano más sofisticado. Dentro del RZF las empresas de alta tecnología lideran el crecimiento en IED y exportaciones, posicionando al país como el cuarto país exportador de productos de alta tecnología en el mundo (primero en Latinoamérica), medido como la participación de estas exportaciones en las exportaciones totales de la industria manufacturera (Gamboa, 2011).

El establecimiento de este tipo de IED en nuestro país a largo plazo permea, como resultado directo, la ampliación de nuestra oferta exportable. Según estudio del BID, "observamos una diversificación de las exportaciones, según la cual los componentes electrónicos e instrumentos de medicina adquieren cada vez más importancia mientras se contrae la participación de frutas tropicales y café" (Rodríguez-Clare, 2003)

Así, por ejemplo durante el 2011 se crearon un aproximado de 25 mil empleos, un tercio de los cuales tuvo como origen el sector de alta tecnología ubicado en zona franca, con una inversión de \$470 millones. Otra área que se vuelve cada vez más importante en la generación de empleo es el sector de servicios que aportó uno de cada cinco empleos generados este año, con 21 proyectos nuevos, en diferentes áreas como contabilidad, finanzas, ingeniería y animación digital. Casi el 30\% de la IED se encuentra en zonas francas (El Financiero, 16-01-12).

La apertura de telecomunicaciones, por su parte, representa un nuevo segmento de inversión extranjera, ligado a la apertura del sector de telecomunicaciones costarricense. Al momento de elaborar este artículo, no se tienen los datos del último trimestre del 2011, pero los datos hasta 
setiembre revelan que las inversiones del sector de telecomunicaciones representan el 24,8\% de los $\$ 1558$ millones que el país captó en IED, desde enero hasta setiembre. (La Nación, 17-01-12).

Asimismo, en datos de PROCOMER, en materia de encadenamiento de la IED al tejido productivo, pero en especial a las PYMES, se han dado resultados positivos, en los últimos años. Un estudio del 2011 de esta entidad nos proporciona datos al respecto:

La cantidad de negocios realizados por PROCOMER pasó de 1 negocio (se refiere a negocios con Pymes, nota de la autora) en el 2001 a 240 negocios realizados en 2010 y el monto presentado en primeros negocios pasó de US\$0.8 millones en 2001 a US\$8.2 millones en 2010, siendo los sectores de empaque y embalaje, metalmecánica, plásticos, y servicios tecnológicos los que presentan mayor cantidad de negocios y montos negociados. En 2010, un estudio del BID estimó que el monto de negocios acumulado en la década fue de US\$840 millones (Gamboa, 2011).

En esta visión panorámica positiva, aunque tenemos la mayor inversión extranjera de alta tecnología per cápita de la región, existe la legítima preocupación por parte de la IED radicada en suelo costarricense, de si la demanda de personal especializado está tocando el techo de nuestras capacidades de oferta profesional y técnica.

Las empresas que prefieren invertir en Costa Rica no lo hacen por el bajo precio de su mano de obra. Salarios más bajos son importantes para la IED, pero no son el único factor, ya que más bien, la IED busca una buena relación "costobeneficio" generada por una alta productividad.

Ese no es el parámetro en el que competimos por IED. Competimos ofreciendo una población educada y un excelente acervo humano. Las empresas que vienen a Costa Rica afirman que nuestros profesionales tienen una curva de aprendizaje 50\% más rápida si se compara con empleados norteamericanos. Se considera que la mano de obra no especializada es comparablemente más costosa si se compara con otros países centroamericanos o asiáticos, pero la mano de obra profesional y calificada es considerada más competitiva que en Estados Unidos, México y Chile. Sin embargo, se reitera la manifiesta preocupación de la misma IED de si Costa Rica se encuentra al borde del límite de su oferta profesional y de si los volúmenes existentes de nuestra oferta de personal técnico responden adecuadamente a sus necesidades de demanda laboral.

\section{Zona Franca y encadenamiento productivo}

Para Costa Rica, el esfuerzo de desarrollar políticas públicas de fomento a las exportaciones nace de su incorporación al Mercado Común Centroamericano (MCC), en la década de 1960. Se buscó amortiguar las dificultades propias de una economía pequeña y dependiente de unos pocos cultivos de exportación por medio de la producción y exportación de productos industriales a Centroamérica.

Estos mecanismos de promoción de exportaciones se complementaron, en la década de los noventa, con la adhesión de Costa Rica al GATT, como un giro político sistemático a la apertura comercial. Como señala un reciente estudio de la CEPAL "con la paulatina inserción internacional de las economías centroamericanas, las ZF se convirtieron en un instrumento importante para promover la IED y, por medio de ésta, las exportaciones, para así facilitar la transición del modelo de sustitución de importaciones a otro de regionalismo abierto" (Martínez, 2011).

Hubo un período de fomento pernicioso a las exportaciones. Se trataba de dar al sector exportador certificados de abonos tributarios, transferibles y negociables en el mercado, de acuerdo 
al volumen exportado -o aparentemente exportado-. Los abusos fueron enormes y el modelo entraba en contradicción con el sistema multilateral de comercio, por ser considerados subvenciones a la exportación. Al adherirse Costa Rica al GATT, el país se comprometió a la eliminación de los Certificados de Abono Tributario (CAT) a partir de 1999.

La adhesión posterior a la OMC en 1995, establece un marco regulatorio internacional, aplicable al país, a través del Acuerdo sobre Subvenciones y Medidas Compensatorias. Se establece ahí, por primera vez, plazos generalizados de adecuación de esos regímenes a las normas de la OMC, para todos los países con regímenes de fomento a las exportaciones, que pudieran catalogarse bajo la figura del subsidio. Ese era el caso del régimen de zonas francas de esa época.

Respondiendo a una mayor apertura comercial, en 1996, se promulgaron la Ley 7557 -Ley General de Aduanas- que establece el Marco Jurídico más general para el régimen tributario de las Zonas Francas (artículo 175 y siguientes), el régimen de perfeccionamiento activo (artículo 179 y siguientes) y el régimen devolutivo de derechos (artículo 190 y siguientes). Estos son los tres regímenes especiales de exportación de Costa Rica.

En 2008, se decretan los reglamentos actuales que regulan los regímenes de Zona Franca, de Perfeccionamiento Activo -ambos en vigenciay de Devolutivo de Derechos -en vigencia a partir del 19 de Marzo del 2009. En el año 2010 entra, finalmente, en vigencia la nueva ley de zona franca, tras arduos -y largos- años de consulta.

De esta forma para fomentar las inversiones con destino a la exportación, tanto para nacionales, pero especialmente para empresas extranjeras, el país ha desarrollado, a lo largo de dos décadas, tres regímenes de fomento a la inversión con fines de exportación. Con estos regímenes, estrechamente interconectados, Costa Rica ha funda- do tradicionalmente sus políticas públicas sectoriales: "zonas francas", "perfeccionamiento activo", y "devolutivo de derechos". Su objetivo ha sido ofrecer un amparo tributario a las inversiones en el país que tengan como fin exclusivo las exportaciones. Con ello se busca incrementar el valor agregado local de su producción, generación de mejores fuentes de empleo, desarrollo industrial local y aumento de la inversión productiva.

Las Zonas Francas han sido catalizadoras de la economía costarricense. Con su nueva ley mejoran las condiciones de las empresas locales para integrarse en la economía mundial, a través de extensos encadenamientos, con empresas de zona franca. En efecto, la nueva ley permite diferentes formas de encadenamiento, como proveedores locales que pueden utilizar materia prima importaba bajo régimen, maquinaria suplida por las empresas de zona franca, junto a materia prima y mano de obra local, en planta física fuera de régimen. Eso crea condiciones muy favorables al encadenamiento de suplidores locales, y producen un incentivo a que las empresas locales se encadenen a la exportación, participando como proveedores locales hacia los mercados mundiales.

A lo largo de las últimas dos décadas, el régimen de Zona Franca ha desempeñado una labor importante en el incremento de las exportaciones, la diversificación de la oferta exportable, la atracción de IED y la generación de empleo en muchos países de América Latina y el Caribe (Granados, 2005). Según Granados:

El impacto de la actividad económica de las ZFEs -propiamente dichas- en ALC sobre el comercio, el empleo y la inversión extranjera es muy importante. En algunos casos, tales como la República Dominicana, Costa Rica, Honduras, El Salvador y Bolivia las ZFEs han sido esenciales para promover y diversificar exportaciones, generar empleo y atraer inversión extranjera (Granados, 2005). 
El auge del régimen de zona franca acompañado políticas públicas e institucionalidad interna a través de la creación de CINDE, a finales de los ochenta, según estudio del BID, "produjo frutos importantes durante los años noventa y permitió al país atraer inversión en sectores de alta tecnología, donde se destacan empresas como INTEL, Abbott Laboratories, Baxter y Procter and Gamble, entre otras" (Rodríguez-Clare, 2003).

Por otro lado, considera un estudio de la OEA que la IED -especialmente ligada a Zona Francaha sido un vehículo importante en la creación de capacidades del acervo humano costarricense e instrumento de la transferencia tecnológica, al puntualizar que:

Las empresas multinacionales que operan en las Zonas Francas de Costa Rica proporcionan capacitación a los proveedores locales. Los ingenieros, técnicos y personal administrativo que anteriormente trabajaban para las empresas multinacionales de las Zonas Francas están ahora trabajando para los proveedores locales. A través de estos y otros mecanismos, la inversión extranjera directa en Costa Rica ha contribuido de forma significativa en la mejora de la base de conocimientos prácticos y especializados de su economía (Monge, 2005).

\section{El impacto de zonas francas en nuestra transformación productiva}

En el caso de Costa Rica, según datos del Comité de Zonas Francas de las Américas del 2005, las exportaciones costarricenses desde Zona Franca representaban ya para el 2000, un poco más de la mitad de sus exportaciones globales y generaban 34000 empleos directos (Granados, 2005). Este impacto ha crecido a lo largo de la última década, alcanzando un crecimiento promedio anual del empleo del 2000 al 2010 del 6,5\% para generar en el último año citado un total de 58,012 empleos directos. El sector de servicios genera, por si solo, un 48\% de este rubro, siendo un segmento esencial con el que la IED ha ido transformando, de forma constante, nuestra realidad productiva.

Con la puesta en vigencia de la nueva ley de Zona Franca, PROCOMER señala que:

En el 2010, año en el cual se concretó la reforma a la Ley de Zona Franca, 29 nuevas empresas de IED de los sectores de servicios, manufactura avanzada, tecnologías limpias y ciencias de la vida, decidieron instalar operaciones en Costa Rica. Estas empresas, en conjunto con las ya instaladas en el país generaron más de 7,000 nuevos empleos dicho año (Gamboa, 2011).

En una mirada panorámica, en el 2010, el Régimen de Zona Franca está compuesto de 256 empresas, donde el sector de servicios representa el $47 \%$ y la industria manufacturera el $44 \%$. Las exportaciones bajo dicho régimen son responsables de más de la mitad de las exportaciones globales del país, en el período 2006-2010. Bajo el rubro de exportaciones de bienes, el sector eléctrico y de electrónica representa el 45\% del total exportado bajo esa modalidad en el año 2010, siendo el mercado estadounidense su principal destino (Gamboa, 2011).

Como veremos en un acápite posterior, 9 de las 10 empresas de componentes electrónicos operan bajo el Régimen de Zona Franca, incluyendo Intel, que bajo la legislación anterior, tuvo un aporte inicial de más de 2 millones de dólares, por lo que no está en un parque de Zona Franca, sino, más bien, cuenta con instalaciones propias.

Como bien señala el estudio de PROCOMER del 2011, existe un fuerte componente de diversificación de la IED que se ha traducido en una correspondiente ampliación de nuestro propio sector productivo y de las capacidades de nuestro recurso humano. 
... hay que destacar que las exportaciones de bienes están menos concentradas en ciertos sectores hoy en día que años atrás, al igual que en términos de destinos, favoreciendo a la diversificación de las mismas en ambas áreas, y que éstas han venido adquiriendo un perfil más tecnológico en el transcurso de los años. En cuanto a sectores, han incursionado por ejemplo instrumentos de precisión y equipo médico, mientras que en cuanto a destinos han tenido crecimientos importantes en participación regiones como Asia (Gamboa, 2011).

No solo en las exportaciones de bienes se ha dado un fuerte incremento con una correspondiente diversificación. Las exportaciones de servicios bajo esta modalidad han tenido un significativo incremento, con un crecimiento promedio anual de un 19,4\%, entre 2006 y 2010 y un incremento en el aporte a las exportaciones globales de servicios, para ese período, que se refleja en un crecimiento del 21,9\% en 2006 a 31,7\% para el año 2010.

Para el 2010, más de la mitad del aporte de la IED (54\%) se encuentra bajo la modalidad de zona franca respondiendo así al tradicional vínculo que ha existido entre IED y Zonas Francas en nuestro país, durante todo su proceso de apertura.

\section{El encadenamiento de la IED}

Ricardo Monge señala que, ya desde el 2005, el fortalecimiento del vínculo entre la IED y el encadenamiento local:"alrededor de 150 empresas costarricenses están actualmente produciendo bienes y servicios que venden a las empresas multinacionales establecidas en las Zonas Francas. Monge recalca que: "Un 79 por ciento de los proveedores locales son microempresas o pequeñas empresas" (Monge, 2005)

Asimismo, PROCOMER señala en su más reciente estudio publicado en el 2011, que: ...el Gasto Nacional en compras de bienes y servicios, que refleja los encadenamientos de empresas ubicadas en el Régimen con empresas proveedoras nacionales, también ha tenido un crecimiento continuo en los últimos cinco años, llegando a US\$1,080 millones en el año 2010, de los cuales los sectores de servicios y alimentaria son los que más contribuyen a este nivel de gasto, con un 37\% y 30\%, respectivamente (Gamboa, 2011).

Establece este mismo estudio los beneficios aportados por este régimen en los últimos años: "para el año 2010, por cada dólar que se exoneró al RZF, se generó un BP (beneficio país) deUS\$8 y en promedio, entre 2006 y 2010, por cada dólar exonerado al RZF, se generó un BP de US\$ 6,3" (Gamboa, 2011).

Las empresas de Zona Franca con sus exigentes requerimientos, han incidido positivamente en los proveedores locales, los cuales han aumentado la calidad de su oferta, según vemos en la figura 3, y esto ha sido factor relevante en que pasemos de la posición 44 al puesto 28 en el índice de calidad de suplidores del Foro Económico Mundial, del 2001 al 2010.

\section{FIGURA 3}

\section{COMPARATIVO DEL ÍNDICE CALIDAD Y CANTIDAD DE ALGUNOS PAÍSES (FORO ECONÓMICO MUNDIAL. EVOLUCIÓN 2001-2010)}

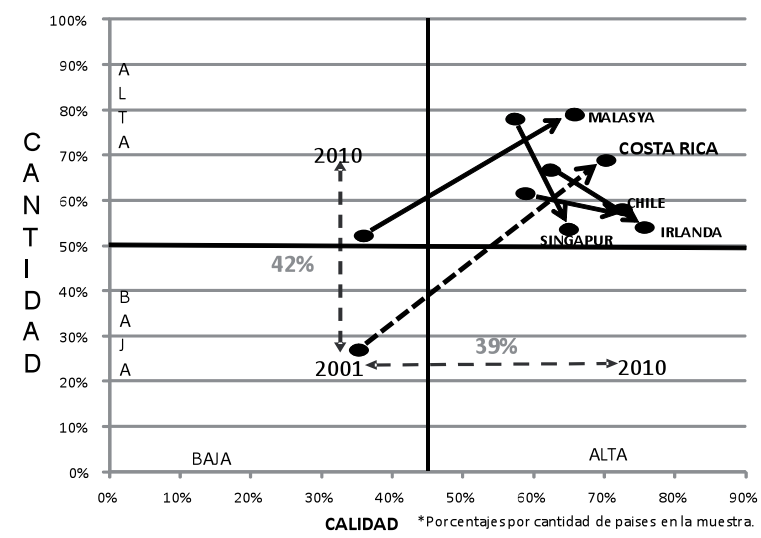

Fuente: Foro Económico Mundial, 2011. 


\section{Impacto en diversos aspectos socioeconómicos}

De la extrapolación del estudio de la OEA -que abarca datos históricos desde 1990 al 2005- y del más reciente estudio de PROCOMER del año pasado se extraen algunos de los datos más pertinentes en materia de generación de empleo, salarios e impacto en el tejido de las Pymes:

- Generación de empleo: La creación de nuevos empleos gracias al establecimiento de empresas en régimen de zona franca se ha incrementado, de forma constante, desde la década de los 1990s, de 7,000 puestos de trabajo, en 1990 a 35 mil en el 2002. Su promedio de crecimiento anual, del 2000 al 2010, ha sido un 6.5\%, generando un total de 58,012 empleos directos, en el 2010.

- Salarios: Dado el hecho de que la oferta de recurso humano del país es un dato que varía lentamente en el tiempo (crecimiento de población, de profesionales y técnicos graduados, etc) el crecimiento de la demanda laboral con origen en la IED se ha traducido en un incremento de los salarios, al haber mayor demanda sobre una misma oferta. Como resultado, se puede atribuir a la demanda de recurso humano de las IED, el diecisiete por ciento del crecimiento de los salarios reales en Costa Rica, durante el período 1991-2002. Esa misma rigidez de la mano de obra disponible, ha tenido como consecuencia que la mayor demanda laboral en RZF tuviera como resultado un continuo incremento en los salarios promedio por trabajador, entre 2006 y 2010, alcanzando la suma de US\$1,028 mensuales por trabajador, 60\% más que el salario promedio pagado por el sector privado.

- Según Monge, ya desde el año 2005, las MIPYMES costarricenses suplían el $99.3 \%$ de la demanda generada por la IED, respondien- do a la distribución siguiente: un 12\% de los suplidores eran microempresas, un 67\% pequeñas y un 20\% medianas. Considera Monge que la IED extranjera directa ha permitido al tejido productivo compuestos por MIPYMES formar parte, de forma indirecta, del proceso exportador. (Monge, 2005)

\section{Cadenas globales de valor}

La plataforma exportadora de Costa Rica aunada a políticas exitosas de atracción de inversión extranjera y regímenes especiales de exportación han impulsado una creciente y eficiente integración del país en las cadenas mundiales de producción. Costa Rica participa en cinco grandes cadenas globales de valor: electrónica, dispositivos médicos, automotriz, aeronáutica/aeroespacial y dispositivos fílmicos.

Según palabras de la Presidenta Chinchilla, en la sesión inaugural de la OMC en setiembre del 2011, en presencia de los más de 150 representantes de la Organización, destacó como logro extraordinario del país que:

...hemos aprendido a colocar nuestros productos en los mercados más exigentes y avanzados y a ser parte de las cadenas internacionales de valor. En 2009, el 43\% de las exportaciones de Costa Rica ya estaban asociadas con las cadenas globales de valor, especialmente con dispositivos médicos, productos electrónicos, automotrices y aeronáuticos. El 36\% del valor de esos productos finales es agregado por la producción costarricense. Con orgullo puedo decir que por las manos de trabajadores costarricenses pasan los mismos productos o servicios que manipulan trabajadores de Malasia, China, Irlanda o Alemania, como parte de líneas de producción que desconocen fronteras (Chinchilla, 2011).

Nuestra participación en las cadenas globales de valor se mide en nuestro posicionamiento 
como el primer exportador de alta tecnología en América Latina; el primero en innovación y el primer exportador per cápita latinoamericano de manufactura. Según datos oficiales, en el año 2011, de 60 empresas que operan en suelo costarricense, ligadas a cadenas globales de valor, 48 de ellas se encuentran amparadas al régimen de zona franca.

Según estudios de PROCOMER:

La mayor variedad y sofisticación de las exportaciones costarricenses, adquirida en los últimos años, está relacionada con que buena parte de la IED está vinculada a cadenas globales de valor. El RZF mantiene una cuota de responsabilidad importante en este tema, ya que el $80 \%$ de las empresas vinculadas a dichas cadenas de valor pertenecen a este régimen. Empresas del RZF participan actualmente en 4 de las cadenas globales de valor más importantes en el sector de manufactura: electrónica, dispositivos médicos, automotriz y aeronáutica/aeroespacial. En total, para el 2009, las exportaciones de dichas cadenas globales de valor representaron un 42.8\% del total de exportaciones de bienes de Costa Rica (Gamboa, 2011).

En este documento nos abocaremos prioritariamente a analizar el desempeño de las cadenas de valor de componentes electrónicos y dispositivos médicos.

\section{Alta tecnología}

El Índice global de competitividad (2011-2012) publicado por el Foro Económico Mundial del 2011 expone que una de las principales fortalezas de Costa Rica es su estado de situación en el clúster de alta tecnología. A pesar del considerable y lamentable desmérito de lo que implica globalmente el descenso de 5 puntos en nuestro posicionamiento en la competitividad internacional, apuntada en este ranquin, todavía sigue dando réditos nuestro excelente desempeño en materia de apertura comercial, políticas de fomento a la Inversión y nuestro enclave de alta tecnología ¿Cómo sería sino?

Independientemente de estos desafíos, Costa Rica todavía muestra un todavía fuerte posicionamiento en la región gracias a sus políticas amigables al comercio con aranceles aduaneros bajos (44th) y pocas restricciones a la IED, y un fuerte sistema educativo ... (23th). Además, el país presenta fuertes niveles de adopción de tecnología (44th) gracias a muchas compañías de alta tecnología e igualmente por una sólida sofisticación en los negocios (35th) e innovación (35th). Todos estos factores facilitan la creación, difusión y adopción de nuevo conocimiento que, si es adecuadamente introducido al mercado, puede generar beneficios significativos (Schawab, 2011).

Reconoce Gamboa, que "en gran medida, la sofisticación de las exportaciones costarricenses tiene que ver con el hecho que buena parte de la IED está vinculada a redes globales de producción que distribuyen diferentes etapas de sus procesos productivos entre distintas sucursales de sus empresas alrededor del mundo". (Gamboa, 2011).

Según datos oficiales del 2011, en la cadena global de valor de productos electrónicos, de 10 empresas que operan en Costa Rica, 9 operan bajo Zona Franca. Se trata de empresas con una planilla promedio superior a los 570 empleados. En promedio, el valor agregado por "manos costarricenses" a esta cadena global de valor es de un 22\%.

Como señala PROCOMER, sus exportaciones para el 2009, superaron la cuarta parte del total de nuestras exportaciones de bienes, cuyo destino principal es China. Esto coincide con la importancia del mercado chino, como país segundo -o tercer- destino de nuestras exportaciones y responde a la concentración de nuestras exportaciones a China en productos electrónicos, principalmente "INTEL". 
Como hemos indicado previamente, la llegada de INTEL a Costa Rica hace 13 años fue el punto de inflexión para que Costa Rica ostentara hoy el primer lugar del planeta en exportaciones de bienes de alta tecnología. La planta de INTEL en Costa Rica diseña, produce y exporta procesadores para computadores y servidores, ofreciendo además servicios financieros, de ingeniería y de soporte técnico. El año pasado, en el 2011, INTEL inauguró un Centro de Desarrollo e Ingeniería de INTEL para desarrollo de hardware y software, siendo ésta su más reciente reinversión en suelo costarricense. Precisamente, este tipo de re-inversión ilustra el potencial de creación de capacidades tecnológicas para nuestro recurso humano.

Según estudio del Instituto Tecnológico de Costa Rica, este tipo de inversión pueden generar "derrames de conocimiento", tanto por el encadenamiento producido con empresas locales, como por la posibilidad de que la creación de capacidades en el recurso humano empleado por la IED, genere posteriormente, nuevos emprendimientos de exempleados que ponen a su propio servicio el entrenamiento recibido durante su labor en las multinacionales. Indican los autores de esta investigación que:

... se puede afirmar que las EMAT (Empresas Multinacionales de Alta Tecnología) que operan en Costa Rica constituyeron, durante el período analizado (2001-2007), una importante fuente de nuevas empresas (aproximadamente 250 por año) y que su permanencia en el tiempo, así como el desempeño son bastante buenos. Este resultado se puede interpretar como una externalidad positiva de la operación de las EMAT en Costa Rica, así como de la política de atracción de inversiones ejecutada desde hace más de veinte años por las autoridades costarricenses (Alegre y otros, 2011).

Señala Gabriela Llobet, directora general de CINDE que la presencia de INTEL y otras compañías similares, ha tenido un fuerte impacto en nues- tro país. Indica que "Costa Rica presentó en crecimiento importante en la última década, ya que desde el 2000 a la fecha la inversión creció en un $20 \%$ y se llegó a crear más de 30 mil puesto de empleo. Eso es lo que coloca a Costa Rica en el primer lugar de Latinoamérica en exportaciones de alta tecnología". Según estas declaraciones oficiales, en este rubro la IED ha crecido en la última década un 20\% generando más de 30 mil puestos de empleo. Pero destaca el potencial y, a la vez, el desafío, de suplir la demanda laboral que implican las proyecciones requeridas por este sector: "para los próximos tres años esta industria requerirá la contratación para la cobertura de 16 mil puestos de trabajo a nivel profesional y técnica" (La Prensa Libre, 2010).

\section{Dispositivos médicos}

En el sector de dispositivos médicos, en el año 2000, se habían radicado en suelo costarricense ocho empresas, con 1.500 personas en la planiIla. Una década después, en el 2010, ya son 32 las empresas de este segmento especializado que emplea 10.000 personas. Eso muestra que el sector de la Industria Médica ha crecido un 375\%, en la última década. (SUMA, 2011)

Este sector permite que Costa Rica participe con fuerza en una de las cadenas globales de valor más relevantes del mundo moderno, donde el avance científico y tecnológico marca los derroteros de todos los sistemas de salud, especialmente en los países desarrollados, con una creciente población adulta mayor sujeta a enfermedades crónicas. Según datos oficiales, sus exportaciones pasaron de US\$87,6 millones en 1998 a US\$1 170 millones en el año 2010, es decir, su valor se ha multiplicado por 13,36 veces.

Según datos de PROCOMER, para el 2011, en la participación de Costa Rica en la cadena global de dispositivos médicos existen 20 empresas integradas verticalmente, operan bajo Zona Franca y su planilla promedio es de 475 empleados. 
Las exportaciones de estas empresas representan ya el 15\% de nuestras exportaciones agregadas y van dirigidas prioritariamente al mercado estadounidense.

Estas empresas multinacionales exportan 81 tipos de dispositivos médicos como equipos cardiovasculares, implantes, catéteres, equipos para infusión y transfusión de sueros y diversos suministros de medicamentos, a más de 72 destinos en el mundo "... en promedio, el 59\% del valor exportado en esta cadena corresponde a valor añadido en Costa Rica, siendo así el sector con el segundo porcentaje más alto de componente doméstico de sus exportaciones..." (Gamboa, 2011).

El crecimiento del sector de dispositivos médicos posiciona a este segmento, según datos de la Coalición Costarricense de Iniciativas de Desarrollo (CINDE), como la tercera fuerza exportadora costarricense (CentralAmericanData, 2011). La importancia de este sector en el país ameritó la firma de un decreto ejecutivo que le otorga carácter de interés público, a partir del 14 de enero del 2012.

La mandataria, Laura Chinchilla, firmó ayer un decreto que declara de interés público la industria de dispositivos médicos y biotecnológicos, con el fin de incentivar el desarrollo de este sector en suelo nacional y de estimular el crédito bancario. El decreto fue firmado en la inauguración de la nueva planta de la empresa costarricense BioTD, la cual creó el Citofem, una nueva prueba de tamizaje de cáncer de cérvix" (La Nación, 15-01- 2012).

Este descubrimiento costarricense de gran acogida y reconocimiento internacional, aunque en su propio suelo de origen no sea utilizado en su sistema de salud pública. El impacto que ha tenido la industria de dispositivos médicos en la propia industria nacional ha sido mayor que ninguna otra de alta tecnología, produciendo, por primera vez, en el caso de BioTD, una empresa de este segmento a partir de capital, talento e investigación totalmente nacional.
De acuerdo a Gabriela Llobet, directora de CINDE, el incremento de este sector -producto directo de la IED-genera fuertes expectativas de generación de empleo de calidad y bien remunerado. Llobet señala a nuestros medios de comunicación que el "salto cualitativo" del sector ha sido posible gracias a la disponibilidad de mano de obra "talentosa". Las empresas ya instaladas han valorado que nuestra mano de obra es talentosa, eficiente, creativa y productiva" (SUMA, 2011). La directora de CINDE agrega que enfrentamos un:

...enorme reto en la generación de trabajadores cada vez más especializados, que se ajusten a la creciente demanda del sector". Apunta a que "Costa Rica necesita técnicos en inyección de plásticos, operarios en metalmecánica, ingenieros industriales, mecánicos y electromecánicos, administradores y contadores bilingües" e indica labores pendientes al precisar la necesidad de que el "Instituto Nacional de Aprendizaje (INA) y las universidades no solo apuntalen su oferta académica hacia estos campos, sino también en investigación y desarrollo en biotecnología (SUMA, 2011).

\section{CONCLUSIONES: LOS DESAFÍOS DE UN CRECIMIENTO DESIGUAL}

Nuestro éxito exportador ha incidido fuertemente en la vida nacional y es verdad de Perogrullo que ha sido la vía correcta. Las brechas de nuestra sociedad no son atribuibles al comercio, sino a la inacción o falta de eficiencia y visión en otras áreas de la vida pública, relacionadas con la equidad en la distribución de la riqueza, en la ausencia de una carga impositiva acorde con nuestras necesidades de inversión pública, descuido educativo, crecientemente negativo entorno empresarial, ausencia de políticas eficientes de acceso al crédito, clientelismo político y corrupción en las más altas esferas de la vida nacional, sin olvidar la cada vez menos eficiente labor de todos los poderes del Estado. 
Curiosamente, el techo de limitaciones al que se acerca nuestro esfuerzo exportador, nace del deterioro de las condiciones sociales en las que se implanta. El avance comercial ya no depende de políticas comerciales, sino de políticas nacionales de transformación del entorno productivo, social, económico y educativo del país. El progreso del comercio solo puede fundarse ahora en políticas extra-comerciales.

Las profundas transformaciones que se han gestado en nuestro aparato productivo no cuentan, sin embargo, con las condiciones óptimas de un entorno de negocio competitivo, de una infraestructura vial y portuaria adecuada, de una oferta laboral acorde a nuestros índices de desempeño exportador y a un crecimiento positivo y encadenado de nuestras pequeñas y medianas empresas con la inversión extranjera directa.

En la antesala de nuestras limitaciones se encuentran también ineficientes y poco evaluadas políticas públicas redistributivas para amortiguar los procesos de concentración de riqueza en los espacios sociales influidos por el sector exportador y permitir que estos sectores contribuyan con la hacienda pública de acuerdo a sus enormes ganancias. Sólo así podría el Estado enfrentar con éxito la persistencia de grandes brechas educativas, sociales y territoriales. Tampoco quedaría fuera de un análisis holístico el balance de la Hacienda Pública, en un país que ostenta el mayor déficit fiscal de América Latina y cuya principal fuente de ingresos sigue siendo la recaudación de aduanas.

Sin lugar a duda, la clara incidencia de los 25 años de apertura comercial costarricense se refleja en las transformaciones de nuestro tejido productivo pero quedan por resolverse brechas de equidad, de contrastes territoriales, de inversión en infraestructura y en educación. El enorme beneficio del comercio, se ha planteado como fin en sí mismo y como única ruta, aislada del entorno socioeconómico en que se gesta y de las transformaciones del aparato estatal que demanda. Eso deja al descubierto la necesidad de un enfoque más integral de desarrollo.

Sin caer en posiciones extremas y valorando el peso decisivo del comercio, debemos reconocer la plena vigencia de muchos cuestionamientos que se hacen a una apertura comercial sin rostro humano. El elevado desempeño de algunos sectores particulares y la transición hacia un nuevo modelo económico se ha producido con un desbalance del desarrollo equilibrado en muchos de los componentes que inciden en nuestro entorno y que pueden afectar la sostenibilidad del modelo.

Más allá de los problemas cotidianos que enfrenta el sector productivo costarricense, hay desafíos nacionales particulares que atañen también directamente a nuestro sector exportador y a la Inversión Extranjera Directa radicada en nuestro suelo. Factores de alta relevancia para mantener el privilegiado "status quo" que ostenta Costa Rica están ligados a una serie de debilidades estructurales tales como deficiencias en la oferta laboral, escasa socialización de los beneficios otorgados por los regímenes de exportación, graves problemas en el entorno de negocios nacional, fuertes rezagos en infraestructura y, no obstante nuestros grandes éxitos en apertura comercial, una balanza comercial que se mantiene, casi permanentemente, deficitaria.

Como conclusión de esta reseña de nuestro desarrollo comercial, se exponen a continuación algunos de los grandes desafíos nacionales, que siendo de un carácter más amplio que el meramente comercial, tocan, influencian, limitan y pueden marcar el techo de nuestro crecimiento comercial.

\section{Desafíos en materia educativa}

Las empresas que prefieren invertir en Costa Rica no lo hacen por el bajo precio de su mano de obra. Como hemos indicado, ese no es el principal parámetro con el que nuestro país compite. El país compite, en gran medida, ofreciendo una pobla- 
ción educada y excelente acervo humano. Como hemos señalado supra, las empresas que vienen a Costa Rica afirman que nuestros profesionales tienen una curva de aprendizaje 50\% más rápida si se compara con empleados norteamericanos, 3 y 4 semanas contra 6 y 8 en Estados Unidos (Garnier, 2010). Se considera que la mano de obra no especializada es comparablemente más costosa si se compara con otros países centroamericanos o asiáticos, pero su mano de obra profesional y calificada es considerada más competitiva que en Estados Unidos, México y Chile.

Sin embargo, estamos a borde del límite de la oferta profesional y nuestra oferta técnica no siempre es apropiada a la demanda. El país está cada vez menos en capacidad de seguir proveyendo una oferta creciente de mano de obra de calidad lo que exige una fuerte inversión en educación y formación, en adecuación curricular, en idiomas en atracción y facilitación para carreras científicas y técnicas, en fin, una eficiente política pública orientada al fortalecimiento sistémico de la calidad educativa.

Hablamos aquí de un cambio de paradigma. El Ministro Garnier dice que "La educación debería devenir en un eje fundamental ya no sólo de la política social, sino de la política económica"(Garnier, 2010).

Este desafío requiere de una nueva mirada a los currículos y a la cobertura de la Educación Superior Pública y muestra la concatenación entre educación y comercio, educación e inversión, educación y encadenamiento empresarial.

Otra vez regresamos a lo que se puede convertir en el talón de Aquiles de nuestro desarrollo, una proporción insuficiente de graduación de secundaria, una matrícula pobre en carreras científicas y técnicas universitarias. Mientras en los países desarrollados casi el 10\% de los estudiantes universitarios están cursando alguna carrera en ingenierías e informática, en nuestro país esas especialidades reúnen a tan sólo un 2.73\% de la oferta de estudios superiores. Par- ticularmente grave es la escasa promoción de carreras científicas entre el segmento femenino que forma ya más 60\% de la matrícula universitaria. Las empresas se quejan cada vez más de una escasa matricula técnica que sea pertinente a la demanda laboral existente.

Nuestras más altas autoridades gubernamentales reconocen los desafíos existentes en materia educativa:

"...es preciso que reorientemos el énfasis de la educación terciaria, para aumentar de manera significativa el número de graduados en ingenierías y ciencias. Todo esto lo vemos estrechamente ligado a la generación o atracción de inversiones que demanden empleos que puedan aprovechar este talento, consolidando así un círculo virtuoso de educación, oportunidad, competitividad y crecimiento" (Chinchilla, 2011).

Tanto las autoridades gubernamentales como la propia IED reconocen que el país enfrenta el desafío de adecuar la oferta técnica y profesional a la demanda laboral planteada por la inversión y por el sector productivo.

\section{Escasa socialización de las nuevas reglas de Zona Franca}

La nueva Ley de Zona Franca es un cuerpo jurídico de tercera generación, orientada a facilitar el encadenamiento productivo de la inversión en ese régimen con el resto de las empresas del país. ¿Cómo permite eso su normativa? La legislación eleva al 50\% el valor que puede ser agregado por una o varias empresas combinadas fuera del régimen, permite el traslado y utilización de maquinaria sin pago de tributos, para la ejecución de este valor agregado fuera de zonas franca y elimina el límite de un año para contratos de encadenamiento productivo de empresas fuera del régimen de zona franca. Esto crea un entorno que puede ser formidable para 
el desarrollo de un enorme tejido de empresas proveedoras nacionales y busca constituir una base firme de la sostenibilidad y asimilación de la transferencia tecnológica.

PROCOMER ha establecido un excelente programa de política pública que ya sobrepasa una década, "Costa Rica Provee", diseñado para promocionar esa vinculación deseada entre inversión extranjera con entramado empresarial local. Pero existe el problema constante de una comunicación estratégica inadecuada, porque como señala la CEPAL, "Costa Rica Provee" se maneja con una lista de 7000 pymes en un sistema de calificación de proveedores. Eso está bien y parecería señalar progreso. Sin embargo, las empresas multinacionales señalan desconocimiento de esos proveedores y dicen que han tenido que crear sus propios departamentos de proveedores locales, para poder encontrar socios nacionales. (170 Informe del Estado de la Nación, 2011)

La problemática señalada es descifrar cómo participar en el encadenamiento de valor más allá de meros servicios de embalaje, ensamblaje u operaciones logísticas, que se reparten la tajada del león en el encadenamiento nacional, sin dejar mucho impacto en el país. El reto es pasar a prestar servicios basados en el conocimiento y las destrezas especializadas existentes en el país, de forma que subamos en la categoría de valor que añadimos, pasando de participar en actividades logísticas a encadenarnos a actividades de mayor valor agregado en investigación y desarrollo.

\section{Deterioro en el desempeño exportador de nuestras pymes}

La recuperación económica de nuestro sector exportador se refleja en un desempeño positivo en el 2010, después de que cayeron nuestras exportaciones, en el 2009, por primera vez en casi dos décadas (COMEX, 2010). En este contexto, el 170 Informe del Estado de la Nación del 2011, señala que el 2010 registró un aumento en el número de Pymes exportadoras. Sin embargo, y en gran medida producto de la inestabilidad de los mercados externos y de un entorno de competitividad interno en condiciones decrecientes, el índice del desempeño exportador de PROCOMER, muestra una tendencia negativa. Indica este informe que:

...entre 2007 y 2010 se registró una reducción significativa en las empresas de este sector calificadas como altamente exitosas y un aumento de las poco exitosas. Una investigación reciente detectó importantes debilidades en el esfuerzo exportador de las pequeñas y medianas empresas (PYMES), sobre todo en lo relativo a su continuidad (170 Informe del Estado de La Nación, 2011).

Este comportamiento muestra la vulnerabilidad de este sector ante condiciones exógenas agresivas y el impacto que tiene, prioritariamente en las empresas de menor tamaño, un entorno doméstico negativo, como lo comprueba el descenso sistemático de nuestros índices en los indicadores del "Doing Business" del Banco Mundial de los años más recientes. (Banco Mundial, 2011). El posicionamiento de Costa Rica en el “Doing Business" del Banco Mundial expresa mejor que cualquier otro razonamiento el rezago del país en los otros ejes de su estrategia de desarrollo. Ahí se dibuja el "nudo gordiano" de tramitología que nuestro país ha ido acumulando, en detrimento de nuestra competitividad y que es especialmente nocivo para el buen desempeño de las MiPymes.

En este índice, nuestro país está clasificado entre los 18 países más rezagados del mundo en el tiempo requerido para iniciar un negocio. Las debilidades que genera la tramitología costarricense y las dificultades de acceso al crédito responden como elemento determinante en la informalidad de estas Mipymes, es causal de mortalidad y, afecta a las mismas Mipymes exportadoras, que son la punta de lanza de este entramado empresarial, con una tasa de mortalidad cercana al 90\% antes de sus cinco años de vida. 


\section{Inversión en I+D}

Una insuficiente base educativa que fomente la creatividad y poca innovación como consecuencia de una pobre inversión nacional en investigación y desarrollo son parte del engranaje actual de debilidades para sostener el nivel actual de atracción de IED.

El plan nacional de ciencia y tecnología 20112014 anota que hasta ahora lo más que CR ha invertido en Inversión y Desarrollo es $0.4 \%$ del PIB. (Chinchilla, 2010). La propuesta del Poder Ejecutivo de que esa inversión llegue hasta el 0,5\% del PIB no parecería mucho para un país de ingreso medio como el nuestro.

Nuestras autoridades están conscientes de este desafío, pero eso no impide fuertes recortes presupuestarios en detrimento de la inversión en esta materia.

\section{Una persistente balanza comercial deficitaria}

Debemos siempre recordar que, no obstante un desempeño excepcional en rubros como nuestra participación en cadenas globales de valor o nuestra amplísima diversificación de la oferta exportable, nuestra balanza comercial muestra una característica constante, que no se ha revertido ni siquiera en los mejores momentos de las últimas dos décadas: es deficitaria.

Como nuestra relación entre importaciones y exportaciones es deficitaria, requerimos para paliar esta debilidad, mantener un desempeño positivo y sostenido a nivel de atracción de la IED. Como indica el especialista de la CEPAL, Jorge Mario Martínez, esta es una problemática a escala centroamericana, de la cual no escapamos:

... la IED se ha convertido en un factor relevante para la estabilidad económica y financiera de los países de la subregión porque contribuye a financiar el déficit en cuenta corriente, generado en parte por un déficit comercial creciente, producto de un incremento mayor de las importaciones que de las exportaciones. Sin embargo, dado que la IED es un factor exógeno a la política nacional de inversiones, sólo puede ser el complemento de dicha política y de la inversión local. La crisis financiera internacional provocó un descenso de 28,3\% promedio anual de la IED entre 2009 y 2010, lo que realza la importancia de la inversión interna para lograr una expansión económica sostenida (Martínez, 2011).

En ese mismo sentido, la autora ha consignado, en ocasiones pasadas, que "nuestro desarrollo está ligado, en el corto plazo, al aumento de exportaciones, y con mayor impacto inmediato, a sus capacidades de Inversión Extranjera Directa. Ambos elementos están ligados a la apertura de mercados" (Govaere, 2009). Pero el déficit de la balanza comercial traza un camino marcado por "un límite para el endeudamiento externo, deja un margen nulo para el ahorro y la inversión productiva y crea fuertes presiones en todas las esferas de la vida económica" (Govaere, 2009). La interrogante es si estaremos, de forma indefinida, en capacidad de seguir incrementando nuestras exportaciones y seguir atrayendo IED, en volúmenes suficientes para paliar un comercio exterior, que visto desde el ángulo de su balanza comercial, es crónicamente deficitario.

Esta perspectiva, sin embargo, se dificulta cuando "tocamos techo" en materia educativa, empeora el entorno de negocios, flaquea la inversión en I+D, aumentan los problemas de infraestructura y últimamente los costos de las empresas se agravan porque deben asumir, de forma sustancial, los crecientes problemas de delincuencia. La interrogante es si este desbalance presente será sostenible en el tiempo.

Esos son algunos de los desafíos del país y dejo fuera de este análisis, múltiples rezagos, producto de un desarrollo desbalanceado, que se plasman en la urgente de inversión de infraes- 
tructura vial y portuaria, en telecomunicaciones, el tema de aprovechamiento pleno de la plataforma centroamericana, con aduanas transfronterizas disfuncionales, sin hablar del desafío que presenta el problema estructural de los enormes contrastes regionales de desarrollo humano.

El desarrollo ha sido una aspiración permanente que está en peligro de caer en el campo de lo fantasioso. "El retroceso de los indicadores de gobernabilidad de Costa Rica solo es superado en América Latina por el de Venezuela, Bolivia y México. ... Hoy tenemos un Poder Ejecutivo que no ejecuta, un Poder Legislativo que no legisla y un Poder Judicial que los sustituye a ambos. Costa Rica ya no es gobernable" (Casas, 2012).

Cada uno de los resultados positivos de nuestra política comercial contiene, en sí mismo, los límites de su propio desarrollo, derivados de las debilidades y desequilibrios presentes en el modelo de estos últimos 25 años. Más allá de los ejes de que han guiado nuestro comercio exterior, se plantea ahora la necesidad de un debido -y faltante- acompañamiento de políticas de Estado en materia fiscal, social, productiva y de competitividad. La apuesta en educación, ciencia y tecnología, inversión en infraestructura y mejoramiento de entorno regulatorio y de trámites requeridas para hacer negocios, son otros tantos capítulos pendientes para que el país pueda dar, finalmente, el nacionalmente deseado salto hacia el desarrollo.

\section{Referencias}

Alegre, J., Monge, R. y Leiva, J. (2011). Creación de Empresas por parte de ex empleados de empresas multinacionales de alta tecnología en Costa Rica. Revista TEC Empresarial 3, 9-20.

ARCE. S. (17 de Enero de 2012). Sector de telecomunicaciones atrajo \$384 millones en inversión extranjera. La Nación. Recuperado el 17 de enero 2012 en: http:// www.nacion.com/2012-01-17/Economia/sector-detelecomunicaciones-atrajo--384-millones-en---inversion-extranjera.aspx
Banco Mundial (2011). Doing Business. Recuperado el 7 de enero del 2012 en: http://www.doingbusiness.org/reports/global-reports/doing-business-2011/

Barquero, M. (24 de junio 2011). Comisario de Comercio Europeo visita el país: UE subraya beneficios que el país tendría con Acuerdo. San José. La Nación.

Casas, K. (10 de enero 2012). Réquiem por un sueño. San José, La Nación.

Castro, L. y Garnier, L. (2010). Costa Rica un país subdesarroIlado casi exitoso. Editorial URUK, San José, Costa Rica.

Central American Data (27 de junio de 2011). Aumentan Empresas de Dispositivos Médicos. Recuperado el 15 de enero del 2012. http://www.centralamericadata.com/ es/article/home/Empresas_de_dispositivos_mdicos_ en_Costa_Rica

Chinchilla, L. (14 de diciembre 2010). Presentación del Plan Nacional de Desarrollo 2010-2014. San José.

Chinchilla, L. (3 de febrero 2011). Inauguración Centro de Desarrollo INTEL. San José. Costa Rica.

Chinchilla, L. (18 de setiembre 2011). Sesión inaugural Foro Público de la OMC 2011: Encontrar respuestas para los desafíos del comercio mundial. Ginebra, Suiza.

Chinchilla, L. (30 de diciembre 2011). Celebración del Día del Exportador. San José, Costa Rica.

Gamboa, F. y Calderón, J. (2011). Balance de las Zonas Francas: Beneficio Neto del Régimen para Costa Rica 20062010, PROCOMER, San José, Costa Rica.

González, A. y Ocampo, F. (2010). Agenda de Comercio Exterior: Informe 2010-Perspectivas 2011. San José: COMEX. Costa Rica.

Govaere, V. (27 de marzo, 2010). Con la vista al frente. San José. La Nación.

Govaere, V. (10 de junio, 2010). El último bastión. San José. La Nación.

Govaere, V. (2011). Resultados y Perspectivas del Comercio Exterior de Costa Rica, Revista Nacional de Administración 2 (1), 7-30, San José. Costa Rica.

Govaere, V. (2009). Centroamérica en Vísperas de un Acuerdo de Asociación con la Unión Europea. EUNED, San José, Costa Rica.

Granados, J. (2005). Las Zonas Francas de Exportación en América Latina y el Caribe: sus defectos en un mundo globalizado. BID, Washington DC. USA. 
Herrera, C. (1990). Las Negociaciones de Costa Rica en el marco del GATT, Serie Comentarios sobre Asuntos Económicos No. 86, Banco Central de Costa Rica, San José, Costa Rica.

Instituto para la Integración de América Latina y el Caribe BID-INTAL (2000). Costa Rica: ante un nuevo escenario en el comercio internacional. BID-INTAL, Buenos Aires. Recuperado el 19 de diciembre 2011 en: http://www.hacienda.go.cr/centro/datos/Articulo/ Econom\%C3\%ADa\%20pol\%C3\%ADtica\%20de\%20 las\%20reformas\%20estructurales\%20en\%20C.R..pdf

La Nación (14 de enero de 2012). Recuperado el 15 de enero de 2012 en: http://www.nacion.com/2012-01-12/ EIPais/NotasSecundarias/N12-BIO.aspx\#proyector

Leandro, C. (4 de enero 2012). Costa Rica lidera exportaciones de tecnología en latinoamericana. La Prensa Libre. Recuperado el 18 de diciembre 2011 en: http://www. prensalibre.cr/pl/nacional/53069-costa-rica-lidera-exportaciones-de-tecnologia-en-latinoamericana.html

Martínez-Piva, J. (2011). Incentivos Públicos de nueva generación para la atracción de la Inversión Extranjera Directa (IED) en Centroamérica. Serie Estudios y Perspectivas CEPAL, México D.F., México.

Ministerio de Comercio Exterior. (1987). Memoria de Labores 1986-1987. COMEX, San José, Costa Rica.

Ministerio de Comercio Exterior (1992). Evolución del Comercio Exterior Perspectivas para 1993. Ministerio de Comercio Exterior, San José. Costa Rica.

Ministerio de Comercio Exterior (2010). Meta exportadora 2010 superada en US $\$ 192$ millones. Recuperado el 1312-2011 en: http://www.comex.go.cr/prensa/Paginas/ CP-1223.aspx

Ministerio de Comercio Exterior. (2010). Superada meta 2010 de atracción de inversión: país atrajo \$1450 millones. Recuperado el 11-12-2011 en: http://www.comex. go.cr/prensa/Paginas/CP-1219.aspx

Ministerio de Comercio Exterior (2010). Recuperado el 15 de enero de 2012 en: http://www.comex.go.cr/ estadisticas/Otras\%20estadsticas/Otras\%20Estadisticas\%20para\%20Web\%20Apertura.pdf
Ministerio de Comercio Exterior (2010). Recuperado el 15 de enero de 2012 en: http://www.comex.go.cr/ estadisticas/Exportaciones\%20comercio\%20de\%20 Costa\%20Rica\%20cifras\%20global/Principales $\% 20$ productos\%20de\%20exportación.pdf

Monge, R., Rosales; J. y Arce, G. (2005). Análisis Costo-Beneficio del Régimen de Zonas Francas. Impactos de la Inversión Extranjera en Costa Rica. Estudios de Comercio, Crecimiento y Competitividad de la OEA. Washington D.C.: USA.

Resumen del Estado de la Nación en Desarrollo Humano Sostenible (2011) Número 17. Programa Estado de la Nación, CONARE, San José, Costa Rica.

Revista Summa (20 de setiembre de 2011). Industria Médica Extranjera diversifica operación en Costa Rica. Recuperado el 15 de enero del 2012 en: http://www.revistasumma.com/economia/5590-industria-medica-extranjera-diversifica-operacion-en-costa-rica.html

Rodríguez-Clare, A.; Sáenz, M.; Trejos, A. (2003). Análisis del crecimiento económico de Costa Rica, Banco Interamericano de Desarrollo, Washington D.C. USA.

Schawab, K. (2011).The Global Competitiveness Report 2011. World Economic Forum, Geneva, Suiza. Recuperado el 2 de enero 2011 en: http://www3.weforum.org/docs/ WEF_GCR_Report_2011-12.pdf

Villasuso, J. (1999) Economía Política de las Reformas Estructurales en Costa Rica. Instituto de Investigaciones Económicas, Universidad de Costa Rica. San José, Costa Rica. Recuperado el 19 de diciembre 2011 en: http://www.hacienda.go.cr/centro/datos/Articulo/ Econom\%C3\%ADa\%20pol\%C3\%ADtica\%20de\%20 las\%20reformas\%20estructurales\%20en\%20C.R..pdf

Vindas, L. (16 de enero de 2012). \$9 de cada $\$ 10$ de inversiones en zona franca son de alta tecnología. El financiero. Recuperado de http://www.elfinancierocr.com/ ef_archivo/2012/enero/22/economia3039629.html el 17 de Enero de 2012

Ocampo, F. (2011). Situación actual y perspectivas del comercio exterior. COMEX, San José, Costa Rica.

Tenorio, E. (2012) Entrevista realizada a Karen Chan, Directora de Unidad de Monitoreo, Ministerio de Comercio Exterior, San José, Costa Rica, 14 de enero 2012. 